Article

\title{
The Low-Carbon Supply Chain Coordination Problem with Consumers' Low-Carbon Preference
}

\author{
Dan Wu and Yuxiang Yang * \\ College of Economics and Management, China Jiliang University, Hangzhou 310018, China; wudan702@163.com \\ * Correspondence: 11a0705096@cjlu.edu.cn
}

Received: 22 March 2020; Accepted: 18 April 2020; Published: 28 April 2020

check for updates

\begin{abstract}
In this paper, we study the supply chain coordination problem between a manufacturer and a retailer regarding consumers' low-carbon preferences. The retailer considers the market demand to determine the order quantity; the manufacturer chooses how to reduce emissions according to the retailer's order quantity. We consider four cases, including the non-emission abatement, the emission abatement of decentralized decision-making, the centralized decision-making and the retailer providing a cost-sharing contract. By comparing the four cases, we find that the case of a retailer providing a cost-sharing contract can coordinate the supply chain, achieving a Pareto improvement for the manufacturer and retailer. In addition, we use the Rubinstein bargaining model to determine the cost-sharing ratio. Finally, numerical simulations are given to analyze the impact of the cost-sharing ratio on the equilibrium results, including the profit and the emission abatement level. Furthermore, we investigate the impact of the cost-sharing ratio and consumers' low-carbon awareness on the profits of the members in the supply chain. We find that the equilibrium results, including the order quantity, the emission abatement level and the profits of the members in the supply chain under contract, are higher than the ones under centralized decision-making. The results show that in the higher low-carbon awareness market, retailers should formulate a reasonable cost-sharing ratio to achieve emission reduction coordination.
\end{abstract}

Keywords: consumers' low-carbon awareness; carbon trading policy; cost-sharing contract; supply chain coordination

\section{Introduction}

The rapid development of science and technology has changed the original life mode of human beings. The exploitation and use of energy are increasing year by year, resulting in the increase of carbon dioxide emissions and the enhancement of the greenhouse effect. With the continuous increase in carbon dioxide emissions, sea-level rise and bad weather occur frequently, causing serious damage to the human living environment. Reducing carbon emissions can achieve the goal of environmental protection, which is an important part of sustainable development. Hence, it is urgent to reduce carbon emissions and develop sustainable production practices.

Enterprises in the supply chain are the main source of carbon emissions. In fact, in order to pursue their own interests, some enterprises often consume resources uncontrollably. Thus, in many countries, to reduce carbon emissions, governments have taken up certain policies, such as carbon trading policy, carbon tax and so on. The carbon trading policy is considered as an effective measure [1]; it provides for an authority to allocate free carbon emission quotas to enterprises and allows them to trade freely in the carbon market. If the enterprise's carbon emissions exceed the quota, it can purchase additional carbon quota in the market. If the enterprise's carbon emissions are less than the carbon quota, the remaining carbon quota can be sold to other enterprises [2]. The advantage of the policy is that it allows some enterprises to reduce their carbon emissions more economically than others [3]. 
At the same time, carbon trading policy has good prospects in reducing carbon dioxide emissions. Take China as an example, where the government has implemented many policies in order to control carbon emission. The most notable success was the development of a carbon trading market. China has developed seven carbon trading centers in 2011. In 2016, more than 2000 enterprises have joined into the carbon trading platforms, and the total carbon quota allocated was about 1.2 billion tons [4]. Since 2017, China has launched the national carbon trading market.

Faced with the deterioration of the environment, people have gradually realized that excessive carbon emissions will affect our living environment, which prompts more and more consumers to enhance their low-carbon awareness. Some consumers tend to pay higher prices to purchase low-carbon products [5]. The trend is encouraging enterprises to change their original production and operation mode and adopt low-carbon technology to produce their products. Many top enterprises, such as Volvo, Wal-Mart and P\&G (Procter \& Gamble), have taken action to reduce carbon emissions [6]. Moreover, more and more attention has been paid to the low-carbon labeling of products. Many household appliances and other electrical products have been labelled with their energy efficiency [7]. Take Haier as an example: The electrical appliance manufacturer has cooperated with its suppliers to establish a low-carbon supply chain [8]. Therefore, consumers' increasing low-carbon awareness have affected their purchasing decisions and thus the enterprises' carbon abatement and operational decisions [9]. It is meaningful to consider consumers' low-carbon awareness in supply chain decision models.

Recently, many studies have proposed coordination mechanisms to improve the performance of a supply chain (e.g., Chen et al. and He et al.). However, the adoption of low-carbon technology will inevitably increase the production cost of enterprises. Hence, some new coordination mechanisms with carbon emissions were studied (e.g., Ren et al. and Song and Gao). Unlike these studies, in this paper, we aim to investigate the following question: In order to meet the requirements for the government's carbon control and enhance enterprises' profits, how should enterprises make reasonable carbon emission reduction decisions? Currently, the upstream and downstream enterprises in the supply chain are more and more closely linked than ever before; thus, the carbon emission reduction decisions of each member in the supply chain will affect other members. Under the carbon trading policy and considering consumers' low-carbon awareness, how does one design a coordination mechanism to encourage each member to actively adopt the carbon emission abatement activities, enhance the profit for the whole supply chain and achieve a win-win situation?

Therefore, in this paper, we study the supply chain, including one manufacturer and one retailer, within the carbon trading policy. We develop decision models for four cases, including non-emission abatement, emission abatement of decentralized decision-making, centralized decision-making and the retailer providing a cost-sharing contract. In these models, we introduce the consumers' low-carbon awareness. First, we build the decision models of the manufacturer and retailer with non-emission abatement, and then construct the models of both decentralized decision-making and centralized decision-making, finding that the cooperative emission abatement case failed to achieve supply chain coordination. Then, we construct a cost-sharing contract model and design coordination mechanism. Finally, we use the Rubinstein bargaining model to determine the cost-sharing ratio. The remainder of this paper is organized as follows. Section 2 provides a brief review of the relevant literature. In Section 3, the basic assumptions and symbols are given. In Section 4, the decision models under four cases are established. The solutions are presented and compared under the four cases. Section 5 provides numerical simulations and sensitivity analyses. Section 6 contains the discussion of the results. Finally, Section 7 shows the conclusions and future research directions.

\section{Literature Review}

Recently, some researchers have studied the supply chain coordination problem. Lind and Hong [10] studied the newsboy issue in two periods. One retailer and one wholesaler used the revenue-sharing contract to coordinate the channel. Chen et al. [11] compared the supply chain decision-making under symmetric and asymmetric demand information, and analyzed the impact 
of price discount contracts, buy-back contracts and revenue-sharing contracts on the supply chain. Yao et al. [12] studied a supply chain, including one supplier and one retailer, and developed the decision models with the newsvendor model. They found the transfer payment and revenue-sharing contract can coordinate the supply chain under the constraints of downside risks. Heydari et al. [13] considered a reverse supply chain and proposed quantity discounts to increase the return of EOL (End-of-Life) products and coordinate the supply chains. Furthermore, some researchers studied coordination problems under uncertain demand. Yao et al. [14] studied a revenue-sharing contract to achieve coordination for a supply chain, including a manufacturer and two competing retailers under stochastic demand. Yin et al. [15] used an optimal discount contract to coordinate a supply chain, including a manufacturer and multiple suppliers with uncertain demand and maintain long-term cooperation among upstream and downstream firms. Some of the literature considered reverse supply chain and closed-loop supply chain (CLSC) coordination problems. Ghosh et al. [16] designed two subscription-based contracts to coordinate a remanufacturing supply chain, including an OEM (Original Equipment Manufacturer) and remanufacturer. Yang et al. [17] considered a reverse supply chain with waste cooking oil recycling and compared a principal-agent contract and quantity discount contract to solve information asymmetry problem. Xie et al. [18] integrated a revenue-sharing contract and channel investment cost-sharing contract for a CLSC with dual channels, including online and offline. Wu et al. [19] designed a revenue-sharing contract to coordinate a CLSC with a manufacturer and two retailers and considered remanufacturing cost disruptions. He et al. [20] gave contract and authorization mechanisms to improve the efficiency of a CLSC.

However, the above literature did not consider the carbon emission reduction. Currently, the carbon emission problem is becoming increasingly prominent; hence, some scholars began to pay attention to low-carbon supply chain coordination problem. Swami and Shah [21] proposed a two-part tariff contract to solve channel coordination for a green supply chain. Ren et al. [22] studied how to allocate carbon emission reduction targets between a manufacturer and a retailer. Lou et al. [23] investigated the investment and pricing problem under emission trading. They proposed a revenue-sharing contract to coordinate the supply chain. They found that the price of the lower-carbon products is high to consumers, so the government should make policies to keep the price low and achieve emission abatement targets. Dong et al. [24] studied a revenue sharing contract, buy-back contract and two-part tariff contract under a cap-and-trade policy, and found that only the revenue-sharing contract can make the supply chain reach the coordination. Toptal and Cetinkaya [25] proposed coordination mechanisms based upon carbon credit sharing for a buyer and a vendor under cap-and-trade and tax policies. Xu et al. [26] studied a wholesale price contract and cost-sharing contract to coordinate an MTO (Make-To-Order) supply chain under a cap-and-trade policy. Peng et al. [27] compared a quantity discount contract with a revenue-sharing contract with a carbon cap-and-trade policy under uncertainty. They found that the former can achieve coordination. Hence, they proposed a revenue-sharing contract with subsidy. Meng et al. [28] considered two competitive firms in which one adopted low-carbon technology and the other did not, and studied the product selection problem with carbon tax. Song and Gao [29] designed a revenue-sharing contract in order to improve the greening level of the products of a supply chain.

Unlike the previous literature, in this paper, we considered that, under a carbon trading policy, the operational decisions of members in the supply chain will change. Considering the different demand markets, given consumers' different low-carbon awareness and thus purchasing behaviors, an enterprise's emission reduction and operational strategies will be affected greatly. Hence, we developed and compared the decision models for four cases under a carbon trading policy. We also introduced the consumers' low-carbon awareness into the models. We design a cost-sharing contract to coordinate the supply chain with carbon emission and use the Rubinstein bargaining model to determine the ratio. Furthermore, we study the effect of the cost-sharing ratio and consumers' low-carbon awareness on the decision results. 


\section{Basic Assumptions and Symbols}

In this paper, we considered a supply chain including a manufacturer and a retailer. According to related research $[30,31]$, retailers such as Wal-Mart dominate the supply chain, so manufacturers are more willing to be consistent with retailers. Therefore, we use the Stackelberg game to study the supply chain, with the retailer as the leader and the manufacturer as the follower. Symbol descriptions are as follows.

Symbol descriptions for:

(1) Model parameters

$\omega$ : the wholesale price of the manufacturer.

$c_{M}$ : the unit production cost of the manufacturer.

$e_{0}$ : the initial carbon emission level per product for the manufacturer.

eg: the carbon emission per product that government allocates to the manufacturer.

$\gamma$ : the coefficient of the manufacturer's carbon emission abatement cost, $\gamma>0$.

$P_{C}$ : the market price of the carbon credit.

$p$ : the retail price of per product for the retailer.

$a$ : the basic market demand, $a>0$.

$b$ : the price sensitivity of the demand, $b>0$.

$c$ : the consumers' low-carbon awareness, namely, the carbon emission abatement sensitivity of the demand, $c>0$.

(2) Decision variables

$e_{M}$ : the carbon emission abatement level per product of the manufacturer, $0 \leq e_{M} \leq e_{0}$.

$q$ : the order quantity of retailer.

$\beta$ : the cost-sharing ratio of retailer, $\beta>0$.

\section{(3) Other notations}

$\pi_{i}^{t}$ : the profit of the member $i$ in model $t ; i \in\{M, R, S C\}$ represents the manufacturer, retailer and supply chain, respectively; and $t \in\{N, D, C, Y\}$ represents the non-emissions abatement case, decentralized emission abatement decision-making case, centralized emission abatement decision-making case and the retailer providing a cost-sharing contract case, respectively.

Considering consumers' low-carbon awareness, we assume that market demand will increase with the increase in emission abatement level, namely $p=a-b q+c e_{M}$, and $p>w$ [32]. The retailer decides the order quantity from the manufacturer according to the market demand.

In a single cycle, the government allocates a certain amount of free carbon allowances to the manufacturer. They can trade carbon allowances at the market. When the manufacturer chooses to reduce emissions, there will be an emission abatement cost. According to the literature [9], we assume that the manufacturer's carbon emission abatement cost function is an increasing function; thus, we define the function as $I=\frac{1}{2} \gamma e_{m}{ }^{2}$. In the meantime, it is assumed that both the manufacturer and retailer are based on complete information and do not consider inventory issues [33].

There are two types of initial carbon allowances: one is a historical basis and the other is the baseline method. The former method is based on the historical emission data of enterprises. The method is simple and easy to operate, but it cannot be distributed according to the latest situation. Hence, people began to choose the latter method. The latter method needs to choose a baseline, and the company's carbon allowance is determined based on the company's output [34]. Therefore, this paper chooses the baseline method as the principle of the government's allocation of carbon allowances. 


\section{Model Establishment and Analysis}

\subsection{Non-Emission Abatement Model}

In the non-emission abatement case, the manufacturer does not participate in the carbon emission abatement: the initial carbon emission of the manufacturer is $e_{0} q$, and the unit free carbon emission that the government allocated to the manufacturer is eg. In a single cycle, the carbon emission of the manufacturer is $E=e_{0}-e g$; when $E$ is greater than zero, the manufacturer needs to buy carbon credits from the carbon market, and when $E$ is less than zero, the manufacturer can sell its remaining carbon credit. In the non-emission abatement case, the sales price is $p=a-b q^{N}$. Manufacturers and retailers pursue their own profit maximization; the profit functions of a manufacturer, retailer and the whole supply chain are as follows:

$$
\begin{aligned}
\pi_{M}^{N}= & \left(w-c_{M}-P_{C}\left(e_{0}-e g\right)\right) q^{N} \\
& \pi_{R}^{N}=(p-w) q^{N} \\
\pi_{S C}^{N}= & \left(p-c_{M}-P_{C}\left(e_{0}-e g\right)\right) q^{N}
\end{aligned}
$$

The manufacturer produces the product according to the retailer's order quantity, and the retailer buys products from the manufacturer according to the market demand. Because the retailer pursues profit maximization, we seek the first-order derivative of $q^{N}$, and make it equal to zero, $\frac{d \pi_{R}^{N}}{d q^{N}}=a-2 b q^{N}-w=0$, from which we can obtain

$$
q^{N *}=\frac{a-w}{2 b}
$$

Thus, the profits for the manufacturer, retailer and the whole supply chain are

$$
\begin{gathered}
\pi_{M}^{N *}=\left(w-c_{M}-P_{C}\left(e_{0}-e g\right)\right) \frac{a-w}{2 b} \\
\pi_{R}^{N *}=\frac{(a-w)^{2}}{4 b} \\
\pi_{S C}^{N *}=\frac{\left[a+w-2 c_{M}-2 P_{C}\left(e_{0}-e g\right)\right](a-w)}{4 b}
\end{gathered}
$$

\subsection{The Emission Abatement Model}

\subsubsection{The Decentralized Decision-Making Model}

In the decentralized decision-making case, in order to undertake social responsibility or seek higher profits, the manufacturer will put investment in carbon emission abatement technology, and the emission abatement cost is $\frac{1}{2} \gamma e_{M}^{2}$. After the low-carbon measures are taken, the carbon emission per product can be reduced $e_{M}$, and the market demand is $p=a-b q+c e_{M}$. In a single cycle, the carbon emission of a manufacturer is $E=e_{0}-e g-e_{M}$.

Manufacturers and retailers pursue to maximize their profits under decentralized decision-making. The retailer firstly determines the optimal order quantity, and then the manufacturer determines its emission abatement level based on the retailer's order quantity.

The profits of the manufacturer, retailer and the whole supply chain, respectively, are as follows:

$$
\begin{gathered}
\pi_{M}^{D}=\left[w-C_{M}-P_{C}\left(e_{0}-e g-e_{M}\right)\right] q^{D}-\frac{1}{2} \gamma e_{M}^{D 2} \\
\pi_{R}^{D}=(p-w) q^{D} \\
\pi_{S C}^{D}=\left[p-C_{M}-P_{C}\left(e_{0}-e g-e_{M}\right)\right] q^{D}-\frac{1}{2} \gamma e_{M}^{D 2}
\end{gathered}
$$


This model is solved by backward induction; we can firstly obtain the manufacturer's optimal emission abatement level.

The manufacturer pursues its profit maximization, so the optimal emission abatement level is the level when the benefits are maximized; that is, the first-order derivative of $e_{M^{\prime}}^{D}$ namely, $\frac{d \pi_{M}^{D}}{d e_{M}^{D}}=P_{C} q^{D}-\gamma e_{M}^{D}$. When $\frac{d^{2} \pi_{M}^{D}}{d e_{M}^{D}}=-\gamma<0, \pi_{M}^{D}$ is a unique maximum. In the meantime, the first-order condition of $e_{M}^{D}$ is zero, namely, $\frac{d \pi_{M}^{D}}{d e_{M}^{D}}=0$. The optimal emission abatement level of the manufacturer is

$$
e_{M}^{D}=\frac{P_{C} q^{D}}{\gamma}
$$

Substituting Equation (11) into Equation (9), we find $\frac{d \pi_{R}^{D}}{d q^{D}}=a-w-2 q^{D}\left(b-\frac{c P_{C}}{\gamma}\right)$. When $\frac{d^{2} \pi_{R}^{D}}{d q^{D 2}}=$ $-2\left(b-\frac{c P_{C}}{\gamma}\right)<0$, namely, $c<\frac{b \gamma}{P_{C}}, \pi_{R}^{D}$ is a unique maximum. At this time, make $\frac{d \pi_{R}^{D}}{d q^{D}}$ equal to zero, and then the retailer's optimal order quantity is

$$
q^{D *}=\frac{\gamma(a-w)}{2\left(b \gamma-c P_{C}\right)}
$$

Substituting Equation (12) into Equation (11), we have

$$
e_{M}^{D *}=\frac{P_{C}(a-w)}{2\left(b \gamma-c P_{C}\right)}
$$

Substituting Equations (12) and (13) into Equations (8)-(10), the profits for the manufacturer, retailer and supply chain are

$$
\begin{gathered}
\pi_{M}^{D *}=\left[w-C_{M}-P_{C}\left(e_{0}-e g\right)\right] \frac{\gamma(a-w)}{2\left(b \gamma-c P_{C}\right)}+\frac{1}{2} \gamma\left[\frac{P_{C}(a-w)}{2\left(b \gamma-c P_{C}\right)}\right]^{2} \\
\pi_{R}^{D^{*}}=\frac{\gamma(a-w)^{2}}{4\left(b \gamma-c P_{C}\right)} \\
\pi_{S C}^{D *}=\frac{\gamma(a-w)\left\{2\left(b \gamma-c P_{C}\right)\left[a-C_{M}-P_{C}\left(e_{0}-e g\right)\right]-(a-w)\left(b \gamma-c P_{C}-\frac{1}{2 P_{C}^{2}}\right)\right\}}{4\left(b \gamma-c P_{C}\right)}
\end{gathered}
$$

Proposition 1. When the manufacturer investments in emission abatement technology, the profits of the manufacturer and retailer will improve under the decentralized decision-making, but the increase in the manufacturer's profit will be greater than that of the retailer's profit.

Proof. Comparing the profits of the manufacturer and retailer in both the emission abatement and non-emission abatement cases, we can see

$$
\begin{gathered}
\pi_{R}^{D *}-\pi_{R}^{N *}=\frac{\gamma(a-w)^{2}}{4\left(b \gamma-c P_{C}\right)}-\frac{(a-w)^{2}}{4 b}=\frac{c P_{C}(a-w)^{2}}{4 b\left(b \gamma-c P_{C}\right)}>0 \\
\pi_{M}^{D *}-\pi_{M}^{N *}=\frac{P_{C}(a-w)\left\{b \gamma+4 c\left(b \gamma-c P_{C}\right)\left[w-C_{M}-P_{C}\left(e_{0}-e g\right)\right]\right\}}{8 b\left(b \gamma-c P_{C}\right)^{2}}>0 \\
\left(\pi_{M}^{D *}-\pi_{M}^{N *}\right)-\left(\pi_{R}^{D *}-\pi_{R}^{N *}\right)>0
\end{gathered}
$$


According to the proof, when the manufacturer investments in emission abatement technology, the profits of both the manufacturer and retailer increase, but the profit growth of the manufacturer is more than that of the retailer. At this time, as the leader in the supply chain, the retailer will select centralized decision-making to seek the increase of its own profit.

\subsubsection{The Centralized Decision-Making Model}

In the process of centralized decision-making, the profit of supply chain is

$$
\pi_{S C}^{C}=\left[p-C_{M}-P_{C}\left(e_{0}-e g-e_{M}\right)\right] q^{C}-\frac{1}{2} \gamma e_{M}^{C 2}
$$

Finding the second-order derivative of $e_{M}^{C}$ and $q^{C}$ of Equation (17), $\frac{d^{2} \pi_{S C}^{C}}{d e_{M}^{C 2}}<0, \frac{d^{2} \pi_{S C}^{C}}{d q^{C 2}}<0$, there is the optimal emission abatement level and optimal order quantity.

We use a Hessian matrix to verify the existence of the results $[35,36]$. We have

$$
H\left(e_{M}^{C}, q^{C}\right)=\left[\begin{array}{cc}
-\gamma & c+c P_{C} \\
c+c P_{C} & -2 b
\end{array}\right]
$$

According the above Hessian matrix, we can find that, when $2 b \gamma>\left(c+c P_{C}\right)^{2}, \pi_{S C}^{C}$ is the union concave function with respect to $e_{M}^{C}$ and $q^{C}$. Therefore, we get

$$
\begin{gathered}
e_{M}^{C *}=\frac{\left(c+P_{C}\right)\left[a-C_{M}-P_{C}\left(e_{0}-e g\right)\right]}{2 b \gamma-\left(c+c P_{C}\right)^{2}} \\
q^{C *}=\frac{\gamma\left[a-C_{M}-P_{C}\left(e_{0}-e g\right)\right]}{2 b \gamma-\left(c+c P_{C}\right)^{2}}
\end{gathered}
$$

The profits of the manufacturer, retailer and supply chain, respectively, are

$$
\begin{gathered}
\pi_{M}^{C *}=\frac{\gamma\left[w-C_{M}-P_{C}\left(e_{0}-e g\right)\right]\left[a-C_{M}-P_{C}\left(e_{0}-e g\right)\right]}{2 b \gamma-\left(c+c P_{C}\right)^{2}}+\frac{1}{2} \gamma\left[\frac{\left[a-C_{M}-P_{C}\left(e_{0}-e g\right)\right]}{2 b \gamma-\left(c+c P_{C}\right)^{2}}\right]^{2}\left(P_{C}^{2}-c^{2}\right) \\
\pi_{R}^{C *}=\frac{\left.\gamma\left[a-C_{M}-P_{C}\left(e_{0}-e g\right)\right]\right]\left((a-w)\left[2 b \gamma-\left(c+c P_{C}\right)^{2}\right]-\left[b \gamma-c\left(c+P_{C}\right)\right]\left[a-C_{M}-P_{C}\left(e_{0}-e g\right)\right]\right]}{\left(2 b \gamma-\left(c+c P_{C}\right)^{2}\right)^{2}} \\
\pi_{S C}^{C *}=\frac{\gamma\left[a-C_{M}-P_{C}\left(e_{0}-e g\right)\right]^{2}}{2\left[2 b \gamma-\left(c+c P_{C}\right)^{2}\right]}
\end{gathered}
$$

Proposition 2. The centralized decision-making case fails to achieve supply chain coordination.

Proof. Comparing the manufacturer's emission abatement level, retailer's order quantity and the profits of the manufacturer, retailer and supply chain in both decentralized decision-making and centralized decision-making cases, we get

$$
\begin{gathered}
q^{C}-q^{D}=\frac{2\left(b \gamma-c P_{C}\right)\left[w-C_{M}-P_{C}\left(e_{0}-e g\right)\right]+(a-w)\left(P_{C}{ }^{2}+c^{2}\right)}{2\left(b \gamma-c P_{C}\right)\left[2 b \gamma-\left(c+c P_{C}\right)^{2}\right]}>0 \\
e_{M}^{C}-e_{M}^{D}>\frac{2 b \gamma c+2 P_{C}^{2}\left(c+P_{C}\right)}{2\left(b \gamma-c P_{C}\right)\left[2 b \gamma-\left(c+c P_{C}\right)^{2}\right]}>0
\end{gathered}
$$

Similarly, $\pi_{M}^{C}-\pi_{M}^{D}>0, \pi_{R}^{C}-\pi_{R}^{D}<0$. 
The profit of the retailer under centralized decision-making is less than its profit under the decentralized decision. As the leader, the retailer does not choose the centralized decisions and will look for other methods to increase its profit.

From Equation (11) we can see that the increase in the manufacturer's emission abatement level can lead to the increase in the retailer's order quantity. According to Equation (9), with the increase in the retailer's order quantity and the manufacturer's emission abatement level, we can find that the retailer's profit will increase. Therefore, the retailer will provide the contract to encourage the manufacturer to increase its emission abatement level, which will bring them more profits. In this paper, we consider that, in the early stages of production, a retailer provides a manufacturer with the cost-sharing contract that encourages the manufacturer to actively reduce its emission, and promises to bear the emission abatement cost by the ratio of $\beta$. The following will further analyze the decision-making process of both parties when the retailer provides the cost-sharing contract.

\subsection{The Model of the Retailer Providing a Cost-Sharing Contract}

Retailer undertakes the emission abatement $\operatorname{cost}$ in the ratio $\beta$, and then chooses the order quantity according to the ratio. Based on the ratio and the order quantity, the manufacturer decides the optimal emission abatement level to maximize its profit. The process is still a Stackelberg game that is led by the retailer, followed by the manufacturer.

The manufacturer's profit function is

$$
\pi_{M}^{Y}=\left[w-C_{M}-P_{C}\left(e_{0}-e g-e_{M}\right)\right] q^{Y}-\frac{1}{2}(1-\beta) \gamma e_{M}^{Y 2}
$$

The manufacturer pursues its profit maximization, so the optimal emission abatement level is that of maximum profit. That is a first-order derivative of $e_{M^{\prime}}^{Y}$ namely, $\frac{d \pi_{M}^{Y}}{d e_{M}^{Y}}=0$. When $\frac{d^{2} \pi_{M}^{Y}}{d e_{M}^{Y}}=-\gamma(1-\beta)<0$, $\pi_{M}^{Y}$ exists as a unique maximum. Hence, the optimal emission abatement level of manufacturer is

$$
e_{M}^{Y}=\frac{P_{C}}{\gamma(1-\beta)} q^{Y}
$$

The retailer's profit function is

$$
\pi_{R}^{Y}=\left(a-b q+c e_{M}^{Y}-w\right) q^{Y}-\frac{1}{2} \beta \gamma e_{M}^{Y 2}
$$

Substituting Equation (24) into Equation (25), we have:

$$
\pi_{R}^{Y}=\left(a-b q+c \frac{P_{C}}{\gamma(1-\beta)} q^{Y}-w\right) q^{Y}-\frac{1}{2} \beta \gamma\left(\frac{P_{C}}{\gamma(1-\beta)} q^{Y}\right)^{2}
$$

The first-order derivative of $q^{Y}$ is $\frac{d \pi_{R}^{Y}}{d q^{Y}}=a-w-2 q^{Y}\left(b-\frac{c P_{C}}{\gamma(1-\beta)}\right)-\beta \frac{P_{C}^{2}}{\gamma(1-\beta)^{2}} q^{Y}$. When $\frac{d^{2} \pi_{R}^{Y}}{d q^{Y 2}}=$ $-2\left(b-\frac{c P_{C}}{\gamma(1-\beta)}\right)-\beta \frac{P_{C}{ }^{2}}{\gamma(1-\beta)^{2}}<0$, namely, $c<\frac{\beta P_{C}^{2}+2 b \gamma(1-\beta)^{2}}{2 P_{C}(1-\beta)}, \pi_{R}^{Y}$ exists a unique maximum.

When the consumers' low-carbon awareness satisfies $c<\frac{\beta P_{C}^{2}+2 b \gamma(1-\beta)^{2}}{2 P_{C}(1-\beta)}$, we make the first-order derivative of $q^{Y}$ equal to zero. Hence, the retailer's best order quantity is

$$
q^{\gamma_{*}}=\frac{\gamma(a-w)(1-\beta)^{2}}{2 b \gamma(1-\beta)^{2}-2 c P_{C}(1-\beta)+\beta P_{C}{ }^{2}}
$$


Substituting Equation (27) into Equation (24), we can have

$$
e_{M}^{\gamma_{*}}=\frac{P_{C}(a-w)(1-\beta)}{2 b \gamma(1-\beta)^{2}-2 c P_{C}(1-\beta)+\beta P_{C}^{2}}
$$

Substituting Equations (27) and (28) into Equations (23) and (25), the optimal profits of the manufacturer, retailer and the whole supply chain are

$$
\begin{gathered}
\pi_{M}^{\gamma_{*}}=\left[w-c_{M}-P_{C}\left(e_{0}-e g\right)\right] \frac{\gamma(a-w)(1-\beta)^{2}}{2 b \gamma(1-\beta)^{2}-2 c P_{C}(1-\beta)+\beta P_{C}^{2}} \\
+\frac{1}{2} \gamma(1-\beta)\left[\frac{P_{C}(a-w)}{2 b \gamma(1-\beta)^{2}-2 c P_{C}(1-\beta)+\beta P_{C}{ }^{2}}\right]^{2} \\
\pi_{R}^{Y *}=\frac{\gamma(a-w)^{2}(1-\beta)^{2}}{2\left[2 b \gamma(1-\beta)^{2}-2 c P_{C}(1-\beta)+\beta P_{C}^{2}\right]} \\
\pi_{S C}^{\gamma_{*}}=\frac{\left.\gamma(a-w)(1-\beta)^{2}\left\{\left[2 b \gamma(1-\beta)^{2}-2 c P_{C}(1-\beta)+\beta P_{C}^{2}\right]\left[a-c_{M}-P_{C}\left(e_{0}-e g\right)\right]-b \gamma(1-\beta)^{2}(a-w)+c P_{C}(a-w)(1-\beta)\right]\right\}+\gamma P_{C}^{2}\left(\frac{1}{2}-\beta\right)(a-w)^{2}(1-\beta)^{2}}{\left(2 b \gamma(1-\beta)^{2}-2 c P_{C}(1-\beta)+\beta P_{C}^{2}\right)^{2}}
\end{gathered}
$$

Proposition 3. Under the contract, when the cost-sharing ratio is $\beta \in\left[\beta_{1}, \beta_{2}\right]$, the manufacturer's emission abatement level and the retailer's order quantity are higher than those without a contract. We have

$$
\begin{gathered}
\beta_{1}=\frac{-A P_{C}(a-w)+4 b \gamma D\left(c+P_{C}\right)-D P_{C}\left(2 c^{2}+3 c P_{C}+P_{C}{ }^{2}\right)}{4 b \gamma D\left(c+P_{C}\right)} \\
-\frac{P_{C} \sqrt{A(a-w)\left[A(a-w)+2 A(a-w)\left(2 c^{2}+3 c P_{C}+P_{C}{ }^{2}\right)\right]+D^{2}\left[-8 b \gamma\left(c+P_{C}\right)^{2}+\left(2 c+P_{C}\right)^{2}+2 c P_{C}\left[\left(2 c+P_{C}\right)^{2}+2\left(b \gamma-c^{2}-c P_{C}\right)\right]\right]}}{4 b \gamma D\left(c+P_{C}\right)} \\
\beta_{2}=\frac{-A P_{C}(a-w)+4 b \gamma D\left(c+P_{C}\right)-D P_{C}\left(2 c^{2}+3 c P_{C}+P_{C}{ }^{2}\right)}{4 b \gamma D\left(c+P_{C}\right)} \\
+\frac{P_{C} \sqrt{A(a-w)\left[A(a-w)+2 A(a-w)\left(2 c^{2}+3 c P_{C}+P_{C} C^{2}\right)\right]+D^{2}\left[-8 b \gamma\left(c+P_{C}\right)^{2}+\left(2 c+P_{C}\right)^{2}+2 c P_{C}\left[\left(2 c+P_{C}\right)^{2}+2\left(b \gamma-c^{2}-c P_{C}\right)\right]\right]}}{4 b \gamma D\left(c+P_{C}\right)}
\end{gathered}
$$

(Note: $A=2 b \gamma-\left(c+c P_{C}\right)^{2}, D=a-c_{M}-P_{C}\left(e_{0}-e g\right)$ ).

Proof. In order to meet government policy requirements, and to develop their green reputation and seek higher profits, companies will actively carry out carbon emission abatement to produce more low-carbon products. When $e_{M}^{Y}-e_{M}^{C}>0$, the cost-sharing ratio satisfies the interval of $\beta \in\left[\beta_{1}, \beta_{2}\right]$, and the manufacturer is more motivated to reduce emissions. The emission abatement level with a contract in this range is higher than those when the contract is not provided.

Proposition 4. Through the design of the contract, when the cost-sharing ratio is $\beta \in[\beta, \bar{\beta}]$, the profits of retailer and manufacturer are higher than the profits under the centralized decision-making. $\bar{W} e$ have

$$
\begin{aligned}
\underline{\beta}= & \frac{\omega^{2} A^{2}++a A^{2}(a-2 w)+D A(a-w)\left[P_{C}^{2}-2\left(2 b \gamma-c P_{C}\right)\right]+c P_{C}\left(P_{C}^{2}+2 c+3 c P_{C}\right)+b \gamma\left[2\left(2 b \gamma-c P_{C}\right)-\left(c+P_{C}\right)^{2}\right]}{A(a-w)[A(a-w)-4 b D \gamma]+4 b \gamma D^{2}\left(b \gamma-c^{2}-c P_{C}\right)} \\
& -\frac{P_{C} \sqrt{A(a-w)\left[2 A(a-w)+A(a-w) D\left(2 c+P_{C}\right)^{2}-8 b \gamma\right]+D^{2}\left[b \gamma\left(8 b \gamma-12 c^{2}-12 c P_{C}-P_{C}{ }^{2}\right)+c P_{C}\left(2 c+P_{C}\right)^{2}\right]}}{A(a-w)[A(a-w)-4 b D \gamma]+4 b \gamma D^{2}\left(b \gamma-c^{2}-c P_{C}\right)} \\
\bar{\beta} & =\frac{\omega^{2} A^{2}++a A^{2}(a-2 w)+D A(a-w)\left[P_{C}^{2}-2\left(2 b \gamma-c P_{C}\right)\right]+c P_{C}\left(P_{C}{ }^{2}+2 c+3 c P_{C}\right)+b \gamma\left[2\left(2 b \gamma-c P_{C}\right)-\left(c+P_{C}\right)^{2}\right]}{A(a-w)[A(a-w)-4 b \nu]+4 b \gamma D^{2}\left(b \gamma-c^{2}-c P_{C}\right)} \\
& +\frac{P_{C} \sqrt{A(a-w)\left[2 A(a-w)+A(a-w) D\left(2 c+P_{C}\right)^{2}-8 b \gamma\right]+D^{2}\left[b \gamma\left(8 b \gamma-12 c^{2}-12 c P_{C}-P_{C}{ }^{2}\right)+c P_{C}\left(2 c+P_{C}\right)^{2}\right]}}{A(a-w)[A(a-w)-4 b D \gamma]+4 b \gamma D^{2}\left(b \gamma-c^{2}-c P_{C}\right)}
\end{aligned}
$$


Proof. In order to achieve supply chain coordination, when providing the contract, the profits of the manufacturer and retailer should be higher than the ones of the centralized decision, so the following inequality group should be satisfied:

$$
\left\{\begin{array}{c}
\pi_{M}^{Y}>\pi_{M}^{C} \\
\pi_{R}^{Y}>\pi_{R}^{C}
\end{array}\right.
$$

Solving the problem, the cost-sharing ratio borne by the retailer satisfies $\beta \in[\underline{\beta}, \bar{\beta}]$.

Manufacturers and retailers all hope to make more profit for themselves in a given range, and a manufacturer hopes the ratio to be closer to $\bar{\beta}$, while a retailer hopes the ratio to be closer to $\beta$. So, both parties can use the Rubinstein bargaining model [37] to determine the ratio. The Rubinstein bargaining model, using the complete information dynamic game method, simulates an indefinite bargaining process, getting a refined equilibrium solution in the $(0,1)$ which is $\rho=\frac{1-\tau_{2}}{1-\tau_{1} \tau_{2}}$, and $\tau_{1}, \tau_{2}$ represent, respectively, the discount factors of the manufacturer and retailer, also representing patience. In other words, the one with the greater tolerance will obtain more benefits, and vice versa.

According to the Rubinstein bargaining model, the cost-sharing ratio of the retailer is

$$
\beta=\rho \Delta \beta=\frac{1-\tau_{2}}{1-\tau_{1} \tau_{2}}(\bar{\beta}-\underline{\beta})+\underline{\beta}
$$

The cost borne by the manufacturer is

$$
1-\beta=1-\frac{1-\tau_{2}}{1-\tau_{1} \tau_{2}}(\bar{\beta}-\underline{\beta})-\underline{\beta}
$$

According to Equation (32), we obtain, respectively, the first-order derivative of $\tau_{1}, \tau_{2}, \frac{d \beta}{d \tau_{1}}>0$, $\frac{d \beta}{d \tau_{2}}<0$. That is, as a manufacturer's patience increases, a manufacturer can afford less emission abatement costs and its own revenue will increase; as a retailer's patience increases, a retailer can also afford less emission abatement cost and its own revenue will increase.

\section{Numerical Simulations}

Based on the above model, the following numerical simulations were made to validate and support the above conclusions. According to the basic relationships $c<\frac{b \gamma}{P_{C}}$ and $2 b \gamma>\left(c+c P_{C}\right)^{2}$, we give the values assigned to different parameters as follows: We can assume that in the product market, the basic market demand is 100 and the price sensitivity of demand is 20; for the manufacturer, the wholesale price per product is 10 , the unit production costs is 5 , the initial carbon emissions per product is 0.05 and coefficient of carbon emission abatement cost is 50; and under the government's carbon trading policy, we set the market price of carbon credit as 5 and the carbon emissions per product that the government allocates the manufacturer as 0.03 . We use MATLAB software to solve the models.

\subsection{The Impact of the Cost-Sharing Ratio on the Profits of the Manufacturer and Retailer}

The following analyzes the impact of the cost-sharing ratio on the profits of the manufacturer and retailer. We suppose the consumers' low-carbon awareness is 5 . The impact of the cost-sharing ratio on profits for the manufacturer and retailer is showed in Figure 1. The horizontal axis represents the cost-sharing ratio, and the vertical axis represents the profit for the manufacturer and retailer under non-contract and contract scenarios.

It can be seen from the Figure 1 that the retailer's profit under contract begins to decline when $\beta \in(0.63,1)$. When $\beta \in(0.93,1)$, because the profit of the retailers under contract is lower than one under non-contract, the retailer will no longer provide the contract. When $\beta \in(0.49,1)$, the manufacturer's profit under contract is higher than the one under non-contract and grows rapidly in the range of $(0.72$, 0.92). Hence, in this range, the manufacturer is more willing to cooperate with the retailer to reduce 
emissions. It can be seen from the figure that, in order to maximize their profits, when they design and negotiate the contract mechanism, a manufacturer hopes the retailer to undertake more emission abatement costs, and the retailer hopes the manufacturer to undertake more emission abatement costs.

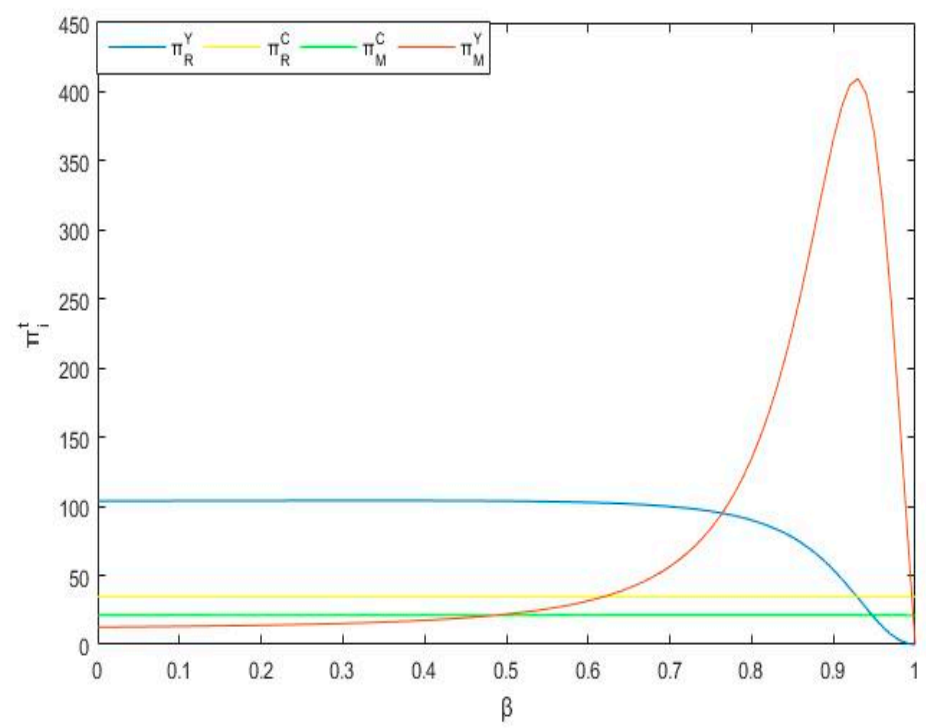

Figure 1. The impact of the cost-sharing ratio on profits for the manufacturer and retailer.

\subsection{The Impact of the Cost-Sharing Ratio on the Emission Abatement Level of the Manufacturer}

The following analyzes the impact of the cost-sharing ratio on the emission abatement level of manufacturer. We also suppose the consumers' low-carbon awareness is 5 . Figure 2 shows the impact of the cost-sharing ratio on the emission abatement level for the manufacturer. The horizontal axis represents the cost-sharing ratio, and the vertical axis represents the emission abatement level of the manufacturer under non-contract and contract scenarios.

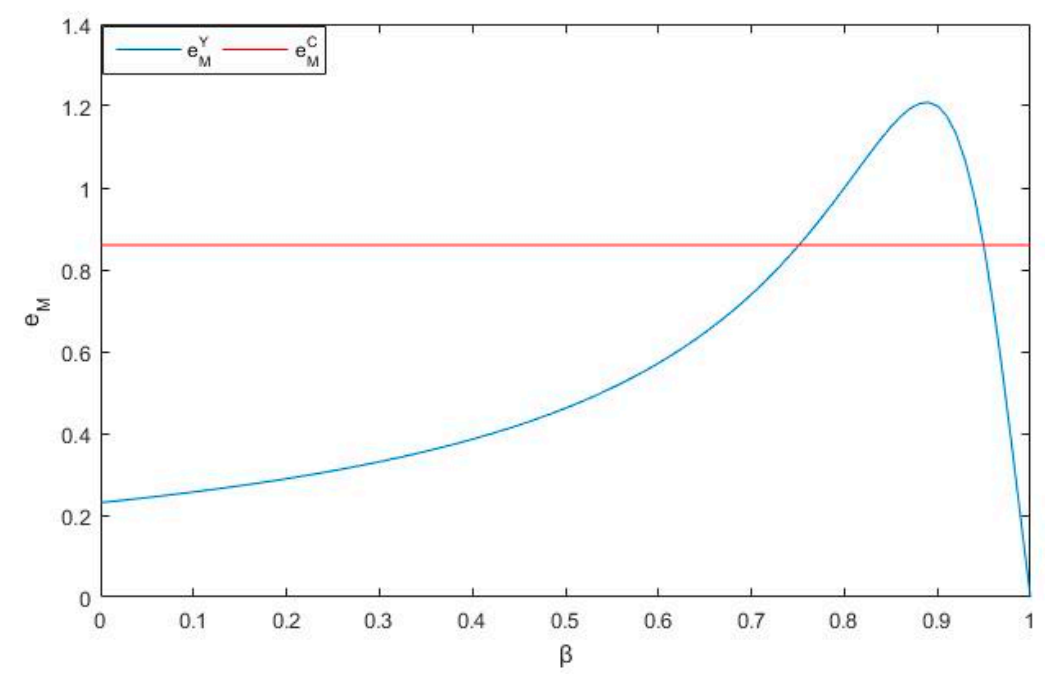

Figure 2. The impact of the cost-sharing ratio on the emission abatement level for the manufacturer.

It can be seen from the Figure 2, when the cost-sharing ratio is about $(0.73,0.95)$, the manufacturer's emission abatement level under contract is higher than one under non-contract. In addition, in the range of $(0.95,1)$, the emission abatement level under contract is lower than one under non-contract. It can be seen from Figure 1 , in the range of $(0.93,1)$, retail will no longer provide the contract, which will make the enthusiasm of the manufacturer to reduce emissions weakened. 
5.3. The Impact of the Cost-Sharing Ratio and Consumer Low-Carbon Awareness on the Profits of the Manufacturer and Retailer

The following will further study the impact of consumers' low-carbon awareness on the profits of the manufacturer and retailer. The basic assumptions remain unchanged. According to the range of the low-carbon awareness $2 b \gamma>\left(c+c P_{C}\right)^{2}$ in Section 3, we set the interval as $c \in[0,8]$.

Figure 3 depicts the changes of the retailer's profit under the influence of the two variables, including the cost-sharing ratio and consumers' low-carbon awareness. On one hand, it can be seen from the Figure 3 that the retailer's profit increases with the increase in the low-carbon awareness; on the other hand, when $\beta \in(0.63,1)$, the profit will decrease with the increase in the cost-sharing ratio. As a result, when $\beta \in(0,0.63)$, the retailer is more willing to take on more costs in a highly sensitive market to encourage the manufacturer to reduce emissions.

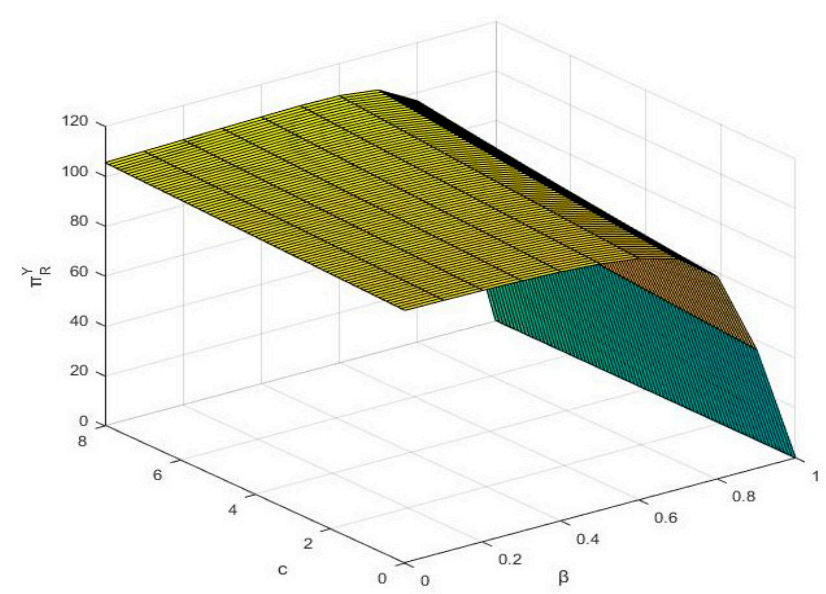

Figure 3. The impact of the cost-sharing ratio and consumers' low-carbon awareness on the profit of the retailer.

Figure 4 depicts the changes in the manufacturer's profit under the two parameters, including the cost-sharing ratio and emission abatement sensitivity. It can be seen from the Figure 4 , on one hand, in the range of $(0.72,0.92)$, the impact of consumers' low-carbon awareness on manufacturing profits is more obvious than that in the range of $(0,0.72)$. On the other hand, in the range $(0.49,0.92)$, the manufacturer's profit increases with the increase in consumers' low-carbon awareness. That is, when a retailer bears more emission abatement costs, the manufacturer will be more active in reducing emissions. Especially when consumers have low-carbon preferences, the manufacturer is more willing to cooperate with the retailer to reduce emissions and promote their own profits.

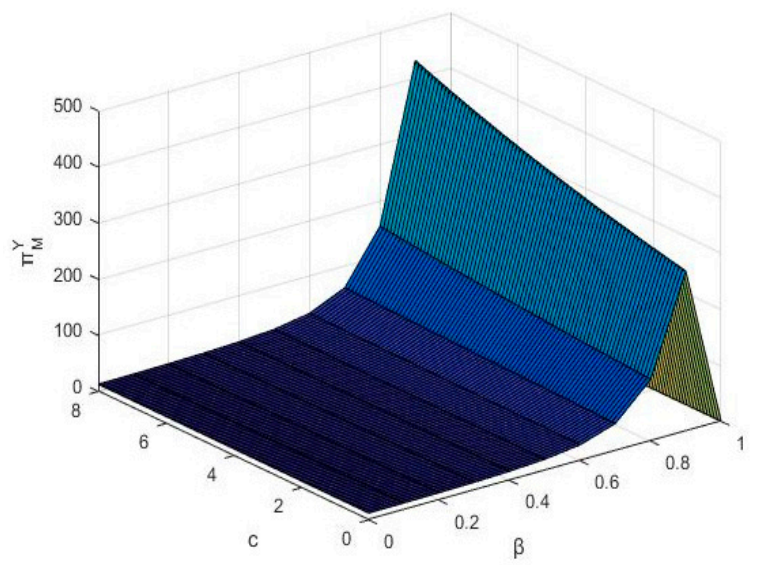

Figure 4. The impact of the cost-sharing ratio and consumers' low-carbon awareness on the profit of the manufacturer. 


\section{Discussion of Results}

From the numerical simulation, we can find that, with the increase in the cost-sharing ratio, the profit of the manufacturer will increase, and the manufacturer will choose to reduce carbon emissions. When the ratio reaches a certain value, the profit of the manufacturer will exceed its profit under centralized decision-making, but the profit of the retailer will begin to decline. When the retailers bear a high cost-sharing ratio, it will cause an increase in the retailers' costs that result in the decline of its profit. Therefore, the retailer should choose a reasonable ratio to ensure that its profits will not drop; meanwhile, the manufacturer can be encouraged to reduce carbon emissions.

Furthermore, we find that the increase in the manufacturer's emission reduction level will lead to the increase of order quantity, so retailers should cooperate with the manufacturer to reduce emissions and bear a certain proportion of the emission reduction costs. When the manufacturer and retailer reach a cooperative emission reduction contract, the retailer will choose to bear a reasonable emission reduction cost to maximize the profits of both sides.

Furthermore, with the increase in consumers' low-carbon awareness, retailers and manufacturers can gain higher profits through reducing carbon emissions. Hence, in a market with higher low-carbon awareness, the retailer should set up the optimal ratio to encourage the manufacturer to reduce emissions in order to meet the demand of the market and increase the profits of both sides. Government should take measures to increase the consumers' low-carbon awareness and encourage consumers to choose low-carbon products. This research can provide a decision-making reference for enterprises to formulate effective carbon emission strategies, and can also help government to find valid policies to reduce carbon emissions.

\section{Conclusions and Future Research}

In this paper, we studied the supply chain coordination between a manufacturer and a retailer under a carbon trading policy. The supply chain coordination is realized by an increase in the manufacturer's emission reduction and profit, and an increase in the retailer's order quantity and profit. By comparing the four cases, including non-emission abatement, emission abatement of decentralized decision-making, centralized decision-making and a retailer providing a cost-sharing contract, it can be found that the final case can achieve a Pareto improvement $[18,38]$ for the manufacturer and retailer. In the meantime, the optimal results, including the order quantity and emission abatement level, are obtained. Furthermore, we used the Rubinstein bargaining model to obtain the cost-sharing ratio. By numerical simulations, the results show the validity of the proposition in this paper.

Numerical simulations show that the equilibrium results, including the order quantity, the emission abatement level and profits of the members in the supply chain under contract, are higher than the ones under centralized decision-making. We find that the cost-sharing ratio and the consumers' low-carbon awareness have a certain impact on the profits of the manufacturer and retailer. Results show that in the higher low-carbon awareness market, retailers should formulate a reasonable cost-sharing ratio to achieve emission reduction coordination. Above all, this study found that the performance of the whole supply chain can be improved by providing a cost-sharing contract. Moreover, when the retailers formulate their carbon abatement strategies, the changes in emission reduction level and profit of both enterprises should be analyzed in order to provide the satisfactory cost-sharing ratio. In addition, in order to promote the cooperation between enterprises on carbon emissions abatement, the government should take some measures, such as low-carbon propaganda, to increase the consumers' low-carbon awareness. In particular, the model can be used by managers to make carbon emission abatement decisions. Moreover, it can be used by policy makers to analyze their environmental policies in order to promote the sustainable development of the economy.

There are still limitations in this paper worth further research. First, in this paper, we simplified the members of the supply chain to one manufacturer and one supplier. In fact, a supply chain is a complex network including multi layers and multi players. A direct extension of the paper is the case with multiple competing members. Secondly, the model is static in this paper. However, as for each 
firm, carbon emission abatement is a long-term behavior, and long term would be more consistent with reality, although it would complicate the problem. Thus, one can study the long-term models under carbon emission abatement policy. Thirdly, in this model, we assumed information symmetry. In fact, the information is not often symmetrical, which will affect the final decision of both parties and the coordination strategy of the supply chain will also change. It is of interest to analyze the relative decision results of the models under asymmetric information compared to the existing models studied in this paper.

Author Contributions: Methodology, Y.Y.; software, D.W.; validation, D.W.; writing—original draft preparation, D.W.; writing - review and editing, Y.Y.; funding acquisition, Y.Y. All authors have read and agreed to the published version of the manuscript.

Funding: The research was funded by National Natural Science Foundation of China (no. 71972172; no. 71801199; no. 71871206), Humanity and Social Science Planning Foundation of Ministry of Education of China (no.19YJA630101), Philosophy and Social Sciences Planning Foundation of Zhejiang Province (no. 20NDJC114YB).

Acknowledgments: The authors wish to thank the anonymous referees for their valuable comments and suggestions.

Conflicts of Interest: The authors declare no conflict of interest.

\section{References}

1. Zhao, X.-G.; Wu, L.; Li, A. Research on the efficiency of carbon trading market in China. Renew. Sustain. Energy Rev. 2017, 79, 1-8. [CrossRef]

2. Lee, C.F.; Lin, S.J.; Lewis, C. Analysis of the impacts of combining carbon taxation and emission trading on different industry sectors. Energy Policy 2008, 36, 722-729. [CrossRef]

3. Nordhaus, W. The Challenge of Global Warming: Economic Models and Environmental Policy; Yale University: New Haven, CT, USA, 2007.

4. Weng, Q.; Xu, H. A review of China's carbon trading market. Renew. Sustain. Energy Rev. 2018, 91, 613-619. [CrossRef]

5. Basiri, Z.; Heydari, J. A mathematical model for green supply chain coordination with substitutable products. J. Clean. Prod. 2017, 145, 232-249. [CrossRef]

6. Wang, Q.; Zhao, D.; He, L. Contracting emission reduction for supply chains considering market low-carbon preference. J. Clean. Prod. 2016, 120, 72-84. [CrossRef]

7. Baldini, M.; Trivella, A.; Wente, J.W. The impact of socioeconomic and behavioural factors for purchasing energy efficient household appliances: A case study for Denmark. Energy Policy 2018, 120, 503-513. [CrossRef]

8. Li, T.; Zhang, R.; Zhao, S.; Liu, B. Low carbon strategy analysis under revenue-sharing and cost-sharing contracts. J. Clean. Prod. 2019, 212, 1462-1477. [CrossRef]

9. Xia, L.; Hao, W.; Qin, J.; Ji, F.; Yue, X. Carbon emission reduction and promotion policies considering social preferences and consumers' low-carbon awareness in the cap-and-trade system. J. Clean. Prod. 2018, 195, 1105-1124. [CrossRef]

10. Linh, C.T.; Hong, Y. Channel coordination through a revenue sharing contract in a two-period newsboy problem. Eur. J. Oper. Res. 2009, 198, 822-829. [CrossRef]

11. Chen, K.; Liang, J.; Li, J. Information structures and pricing decisions in competing supply chains. J. Syst. Sci. Syst. Eng. 2012, 21, 226-254. [CrossRef]

12. Yao, Z.; Xu, X.; Luan, J. Impact of the downside risk of retailer on the supply chain coordination. Comput. Ind. Eng. 2016, 102, 340-350. [CrossRef]

13. Heydari, J.; Govindan, K.; Jafari, A. Reverse and closed loop supply chain coordination by considering government role. Transp. Res. Part D Transp. Environ. 2017, 52, 379-398. [CrossRef]

14. Yao, Z.; Leung, S.C.; Lai, K.K. Manufacturer's revenue-sharing contract and retail competition. Eur. J. Oper. Res. 2008, 186, 637-651. [CrossRef]

15. Yin, S.; Nishi, T.; Grossmann, I.E. Optimal quantity discount coordination for supply chain optimization with one manufacturer and multiple suppliers under demand uncertainty. Int. J. Adv. Manuf. Technol. 2015, 76, 1173-1184. [CrossRef] 
16. Ghosh, D.; Gouda, S.; Shankar, R.; Swami, S.; Thomas, V.C.; Vinu, C. Strategic decision making under subscription-based contracts for remanufacturing. Int. J. Prod. Econ. 2018, 200, 134-150. [CrossRef]

17. Yang, R.; Tang, W.; Dai, R.; Zhang, J. Contract design in reverse recycling supply chain with waste cooking oil under asymmetric cost information. J. Clean. Prod. 2018, 201, 61-77. [CrossRef]

18. Xie, J.; Zhang, W.; Liang, L.; Xia, Y.; Yin, J.; Yang, G.; Xie, J.; Weisi, Z.; Liang, L.; Yu, X.; et al. The revenue and cost sharing contract of pricing and servicing policies in a dual-channel closed-loop supply chain. J. Clean. Prod. 2018, 191, 361-383. [CrossRef]

19. Wu, H.; Han, X.; Yang, Q.; Pu, X. Production and coordination decisions in a closed-loop supply chain with remanufacturing cost disruptions when retailers compete. J. Intell. Manuf. 2018, 29, 227-235. [CrossRef]

20. He, Q.; Wang, N.; Yang, Z.; He, Z.; Jiang, B.; Yang, Z. Competitive collection under channel inconvenience in closed-loop supply chain. Eur. J. Oper. Res. 2019, 275, 155-166. [CrossRef]

21. Swami, S.; Shah, J. Channel coordination in green supply chain management. J. Oper. Res. Soc. 2013, 64, 336-351. [CrossRef]

22. Ren, J.; Bian, Y.; Xu, X.; He, P. Allocation of product-related carbon emission abatement target in a make-to-order supply chain. Comput. Ind. Eng. 2015, 80, 181-194. [CrossRef]

23. Lou, G.X.; Xia, H.; Zhang, J.Q.; Fan, T. Investment Strategy of Emission-Reduction Technology in a Supply Chain. Sustainability 2015, 7, 10684-10708. [CrossRef]

24. Dong, C.; Shen, B.; Chow, P.S.; Yang, L.; Ng, C. Sustainability investment under cap-and-trade regulation. Ann. Oper. Res. 2016, 240, 509-531. [CrossRef]

25. Toptal, A.; Çetinkaya, B. How supply chain coordination affects the environment: A carbon footprint perspective. Ann. Oper. Res. 2017, 250, 487-519. [CrossRef]

26. Xu, X.; He, P.; Xu, H.; Zhang, Q. Supply chain coordination with green technology under cap-and-trade regulation. Int. J. Prod. Econ. 2017, 183, 433-442. [CrossRef]

27. Peng, H.; Pang, T.; Cong, J. Coordination contracts for a supply chain with yield uncertainty and low-carbon preference. J. Clean. Prod. 2018, 205, 291-302. [CrossRef]

28. Meng, X.; Yao, Z.; Nie, J.; Zhao, Y.; Li, Z. Low-carbon product selection with carbon tax and competition: Effects of the power structure. Int. J. Prod. Econ. 2018, 200, 224-230. [CrossRef]

29. Song, H.; Gao, X. Green supply chain game model and analysis under revenue-sharing contract. J. Clean. Prod. 2018, 170, 183-192. [CrossRef]

30. Chen, K.; Xiao, T. Outsourcing strategy and production disruption of supply chain with demand and capacity allocation uncertainties. Int. J. Prod. Econ. 2015, 170, 243-257. [CrossRef]

31. Wang, N.M.; He, Q.D.; Jiang, B. Hybrid closed-loop supply chains with competition in recycling and product markets. Int. J. Prod. Econ. 2018. [CrossRef]

32. Yalabik, B.; Fairchild, R.J. Customer, regulatory, and competitive pressure as drivers of environmental innovation. Int. J. Prod. Econ. 2011, 131, 519-527. [CrossRef]

33. Zu, Y.; Chen, L.; Fan, Y. Research on low-carbon strategies in supply chain with environmental regulations based on differential game. J. Clean. Prod. 2018, 177, 527-546. [CrossRef]

34. Qi, S.Z.; Wang, B.B. Initial Allowances Allocation in Carbon Trading: Comparison of Modes and Methods. Wuhan Univ. J. 2013, 66, 19-28.

35. Chang, X.; Xia, H.; Zhu, H.; Fan, T.; Zhao, H. Production decisions in a hybrid manufacturing-remanufacturing system with carbon cap and trade mechanism. Int. J. Prod. Econ. 2015, 162, 160-173. [CrossRef]

36. Savaskan, R.C.; Bhattacharya, S.; Van Wassenhove, L.N. Closed-Loop Supply Chain Models with Product Remanufacturing. Manag. Sci. 2004, 50, 239-252. [CrossRef]

37. Rubinstein, A. Perfect Equilibrium in a Bargaining Model. Econometrica 1982, 50, 97. [CrossRef]

38. Zhang, C.-T.; Wang, H.-X.; Ren, M. Research on pricing and coordination strategy of green supply chain under hybrid production mode. Comput. Ind. Eng. 2014, 72, 24-31. [CrossRef]

(C) 2020 by the authors. Licensee MDPI, Basel, Switzerland. This article is an open access article distributed under the terms and conditions of the Creative Commons Attribution (CC BY) license (http://creativecommons.org/licenses/by/4.0/). 